\title{
Review of energy demands and wind resource assessment of the Solovetsky Archipelago
}

\author{
Aleksei Kangash ${ }^{\mathrm{a}}$, Rizwan Ghani ${ }^{\mathrm{b}}$, Muhammad Shakeel Virk ${ }^{\mathrm{b}}$, Pavel \\ Maryandyshev ${ }^{\mathrm{a}}$, Viktor Lubov ${ }^{\mathrm{a}}$, Mohamad Mustafa ${ }^{\mathrm{b}}$ \\ ${ }^{a}$ Northern (Arctic) Federal University, naberezhnaya Severnoy Dviny 17, Arkhangelsk, 163002, Russia \\ ${ }^{b}$ UiT The Arctic University of Norway, Lodve Langes Gate 2, 8515 Narvik, Norway
}

\begin{abstract}
This paper aims to analyse the current situation of the energy system of the remote island territory of Solovetsky Archipelago. The Solovetsky historical and cultural complex was included in the list of UNESCO World Heritage Sites. Diesel fuel, which is used on the archipelago is expensive and pollutes the environment. By using Computational Fluid Dynamics (CFD) based numerical method, this study aims to determine the wind energy potential of the territory, which will cover part of the energy consumption. For the best use of wind potential, several variants of the location of the wind park were analyzed in this study. Thus, using wind energy, as an alternative source, the amount of emissions of harmful substances will be reduced, which is a priority for the Arctic region.
\end{abstract}

Keywords: renewable energy, wind resource assessment, island, remote territory, CFD.

\section{Introduction}

The need to reduce emissions of pollutants into the atmosphere is increasingly focused on the current situation in the global energy system. The transition from fossil fuels to renewable energy sources (RES) is a key strategy aimed at protecting the environment and solving energy supply problems. Concern about the fact that production of energy from renewable sources is not constant and does not satisfy energy demand, has prevented many countries from integrating RES into the national energy systems. However, remote islands often provide ideal conditions for a feasibility study and the creation of independent energy systems based on the use of alternative energy sources, due to lower population density, less energy consumption and extensive land or coastal areas not sufficiently involved in economic activities, which enable the use of alternative energy sources [1]. There are more than 50,000 islands in the world, which accounts for $17 \%$ of the total land area of the globe [2]. At present, there are a number of problems related to the energy supply of the island territories. Islands, located far from the mainland, are often dependent on the import of fossil fuels, which are usually costly due to transportation costs [3,4]. Therefore, remote islands often provide ideal feasibility study conditions for introducing independent energy systems based on the use of alternative energy sources.

Published works on energy supply of the island territories mainly describe the power supply system of the southern territories where the heating load is either absent or has small values. Maldives uses diesel power plants for energy supply. Fuel for the power plants is delivered from the mainland. The solar, wind and energy potential of the Maldives biomass is $9.51 \times 10^{8} \mathrm{MW}$ [5], which is much more than their annual energy consumption. In the work "Integration of optimal combinations of renewable energy sources into the energy supply of Wang-An Island" [1], a comprehensive study was conducted for Van-Ai

*Manuscript received July 16, 2018; revised May 4, 2019.

Corresponding author. Tel+4791729801; E-mail address: mmu021@uit.no

doi: $10.12720 /$ sgce.8.4.430-435 
Island, located west of Taiwan Island, which includes calculating the energy that can be obtained by wind, sun, waves and biomass, as well as a solution to the problem of the inconstancy of energy production.

Canaries are also highly dependent on the export of petroleum products, which account for up to $99 \%$ of the energy consumed. In the work "Mutual adaptability of renewable energy and water-supply systems in islands" [6], a model is proposed, through which the Canaries will completely switch to an energy supply system based only on alternative energy sources by 2050. One example of the successful implementation of wind turbines on remote islands is the Galapagos Islands, Ecuador. In January 2001, an oil tanker struck a reef and spilled about $570 \mathrm{~m}^{3}$ of diesel near San Cristobal - one of the inhabited islands of Galapagos, threatening the irreplaceable plants, birds, and marine life. After this disaster, a global renewable energy project on the Galapagos Islands was implemented in 2007 to reduce greenhouse gas emissions and the risk of another oil spill at this UNESCO World Heritage Site. According to the project, three $800 \mathrm{~kW}$ capacity wind turbines were built. Between 2007 and 2015, wind turbines have supplied, on average, 30 percent of the electricity consumed on San Cristobal, replacing $8700 \mathrm{~m}^{3}$ of diesel fuel and avoiding 21000 tons of carbon dioxide emissions. In addition, monitoring results confirmed that turbines had not killed or injured any of the critically endangered Galapagos seabirds. On the territory of Russia there are remote territories with similar problems. An example is the Solovetsky Islands, which are located in the Arctic zone of the Russian Federation, where the heating load has great importance due to the Arctic harsh climatic conditions. The Solovetsky historical and cultural complex was included in the list of UNESCO World Heritage Sites. On one of the islands there is the Solovetsky settlement, whose population is 898 people. The power supply system of the Solovetsky settlement is isolated.

The purpose of this paper is to review energy demands of Solovetsky Archipelago and to evaluate the potential of wind energy as an alternative source to meet these energy demands. In this study, the current energy system is reviewed, the measurements of the wind speed are analyzed, annual energy production is calculated using modeling. It is hoped that this study will contribute to the development of wind power in the region and will help both scientists and investors in future projects.

\section{Current Problems in the Energy System of Islands}

The production of heat and electric energy is provided by Thermal Power Plant (TPP) and Diesel Power Plant (DPP) equipped with diesel-generator sets and hot-water boilers, the main fuel of which is diesel fuel. Diesel fuel is delivered to the settlement only by sea during the summer sea navigation. The difficulty of delivering fuel by the Northern way increases its cost several times. At the TPP, two dieselgenerator sets with each unit capacity of $823 \mathrm{~kW}$ are installed, and at the DPP - two diesel-generator sets with each unit capacity of $1,000 \mathrm{~kW}$ are available. Calculation of electrical and thermal loads was carried out on the basis of data from the logbooks of the energy supply organization, in which the consumption of diesel fuel is recorded. The average daily capacity in winter was $1440 \mathrm{~kW}$, in summer $-721 \mathrm{~kW}$. The maximum load was $1600 \mathrm{~kW}$.

During the calculation of emissions of harmful substances from diesel-generator sets, operating data on the consumption of diesel fuel were used. Gross emissions of carbon monoxide, nitrogen oxides in recalculation for nitrogen dioxide and sulfur oxides in recalculation for sulfur dioxide are shown in Fig. 1. It is necessary to cover part of the electric load by introducing alternative energy sources in consideration of the amount of pollutant emissions from diesel-generator sets, as well as the cost of transporting diesel fuel to the archipelago. This will reduce the load on the diesel generators, the consumption of diesel fuel and emissions of pollutants. Solovetsky Islands belong to the regions of the Far North, and their climate is significantly influenced by wind. Therefore, it is necessary to analyse the possibility of introducing wind power plants. 


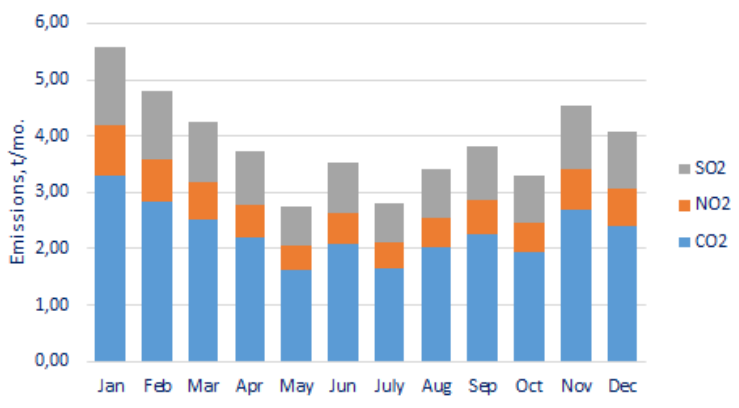

Fig. 1. Monthly emissions of pollutants at Solovetsky Archipelago (2016)

\section{Measurement Data}

It is necessary to calculate the mean wind speed to assess the wind potential of the Solovetsky Archipelago. Mean wind speed is the main characteristic determining wind intensity. In this paper, wind measurements from National Centers for Environmental Information (NCEI) were used [7]. NCEI is the world's largest provider of weather and climate data. The data from an on-site weather station located at the airport of the Solovetsky settlement, which NCEI received from the U.S. Air Force Climatology Center, were analyzed. The data was gathered from April 2012 to February 2018. Unfortunately, the Solovetsky Islands are not equipped with sufficient meteorological equipment. On the islands, there is only one meteorological station, measurements on which only occur at an altitude of $10 \mathrm{~m}$.

\section{Numerical Simulations and Local Wind Climate for Solovetsky Islands}

The average wind condition at the Solovetsky Islands is used in the calibration of the wind resources and in the Annual Energy Production (AEP) estimation. A wind climatology file is generated by using WindRose Pro 3 software, giving the average wind speed distribution divided in velocity intervals (bins) and wind directions (sectors). The original wind speed data are divided in one meter per second bins. Incoming wind directions are divided in 12 sectors, where the first sector is centered around north. The frequency distribution has been fitted to a Weibull distribution.
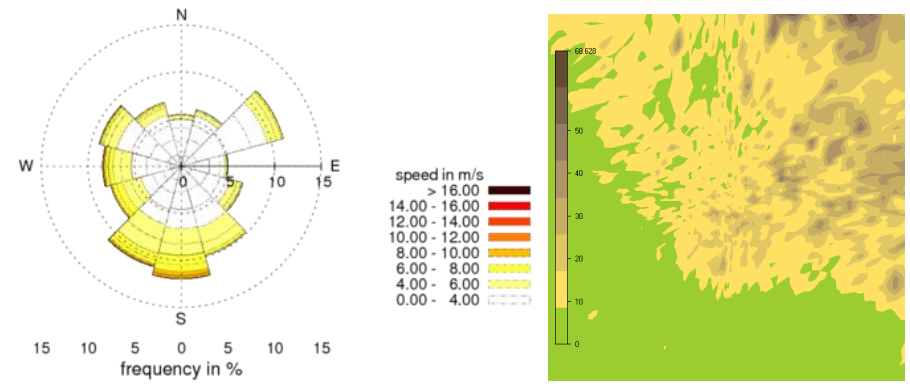

Fig. 2. Local wind rose (left) and terrain elevation (m) (right) for Solovetsky Islands

A numerical wind database is established by CFD simulations using WindSim for Solovetsky Islands. The numerical wind database is used to transfer the wind conditions from the measurement point to the wind turbine hub positions. The source of wind data collection is elaborated in details in the measurement data section. In this study, we are using 5 wind turbines type Vestas V90, hub height: $80 \mathrm{~m}$, capacity of each is: $2 \mathrm{MW}$. The number of wind turbines of this capacity was chosen based on the current energy consumption. However, the increase in energy consumption due to population growth and tourism development for the operational period of wind turbines was also taken into account. A digital terrain model containing elevation and roughness data has been established for the area given in Fig. 2 right part. The coordinate system is UTM, Zone: 36, Datum: WGS84, which is the coordinate system referred to 
whenever coordinates are used in this report. Note that the underlying datasets for elevation and roughness might have different resolution. The following online sources have been used for elevation: ASTER GDEM v2 Worldwide Elevation Data (1 arc-second Resolution) and for roughness: VCF Tree Cover Worldwide 2005 (500 m Resolution). The simulation solver setting is given below in table1. The digital model represents the computational domain where the Reynolds averaged Navier - Stokes equations have been numerically solved. In total 12 simulations have been performed in order to have a $3 \mathrm{D}$ wind field for every 30 degree sector.

Table 1. Solver setting for simulation.

\begin{tabular}{lc}
\hline Height of boundary layer $(\mathrm{m})$ & 500.0 \\
\hline Speed above boundary layer $(\mathrm{m} / \mathrm{s})$ & 10.0 \\
\hline Boundary condition at the top & fix pres. \\
\hline Potential temperature & No \\
\hline Turbulence model & Standard \\
\hline Solver & GCV \\
\hline
\end{tabular}

\section{Results and Discussion}

In this study, 6 years of data from National Centers for Environmental Information (NCEI) has been used. The gross energy production, which is the energy production of the wind farm, is calculated by predicted free stream wind speed distribution at the hub height of each turbine location and the turbine's power curve provided by manufacturers. The free stream wind speed distribution is obtained by the WindSim flow model and the long term on-site wind conditions. Wind turbines extract energy from the wind. The wind speed downstream from the wind turbine is therefore reduced. As the flow proceeds further, the wake is spreading and recovers towards free stream conditions. The wake effect is calculated by the Jensen wake model. Then the potential energy production is obtained by taking into account the wake losses. Two locations were selected to simulate the operation of wind turbines (fig. 3). One of the reasons for this choice is the distance from historical objects aswind turbines should not disturb the view nor create noise. Another reason is the open area, as deforestation on the UNESCO site is prohibited. Furthermore, roads are nearby, which facilitates the transportation and installation of wind turbines.

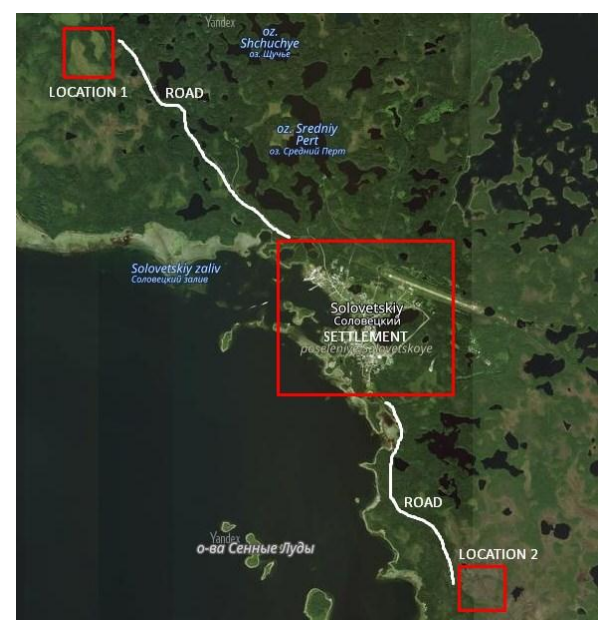

Fig. 3. Locations of wind turbines

The wind resource assessment details are shown in Table 2. CFD simulations have been carried out to get estimations for best fit site area in Solovetsky Islands for the development of wind turbines. 
Table 2. Modeling results.

\begin{tabular}{cccccccccc}
\hline Location & $\begin{array}{c}\text { Turbine } \\
\text { Type, } \\
\text { Hub } \\
\text { Height } \\
(\mathrm{m})\end{array}$ & $\begin{array}{c}\text { No. of } \\
\text { turbines }\end{array}$ & $\begin{array}{c}\text { Capacity } \\
(\mathrm{MW})\end{array}$ & $\begin{array}{c}\text { Gross } \\
\text { AEP } \\
(\mathrm{GWh} / \mathrm{y})\end{array}$ & $\begin{array}{c}\text { Average } \\
\text { wind } \\
\text { speed } \\
(\mathrm{m} / \mathrm{s})\end{array}$ & $\begin{array}{c}\text { Wake } \\
\text { losses } \\
(\%)\end{array}$ & $\begin{array}{c}\text { AEP with } \\
\text { wake } \\
\text { losses } \\
(\mathrm{GWh} / \mathrm{y})\end{array}$ & $\begin{array}{c}\text { Full } \\
\text { load } \\
\text { hours } \\
(\text { hours })\end{array}$ & $\begin{array}{c}\text { Capacity } \\
\text { factor } \\
(\%)\end{array}$ \\
\hline Loc.1 & $\begin{array}{c}\text { Vestas } \\
\text { V90, } 80.0 \\
\text { Vestas }\end{array}$ & 5 & 10.0 & 20.5 & 5.3 & 13.1 & 17.8 & 1781.0 & 20.3 \\
L90, 2 & 5 & 10.0 & 22.4 & 5.6 & 7.9 & 20.6 & 2063.0 & 23.6 \\
\hline
\end{tabular}

Wind resource assessment at location 1 gave the following results: gross AEP is $20.5 \mathrm{GWh} / \mathrm{y}$ and AEP with wake losses is $17.8 \mathrm{GWh} / \mathrm{y}$. From the results, it is clear that wake losses at location 1 are high and amount to $13.1 \%$. For the second location, an acceptable result for the losses $(<10 \%)$ was obtained. Thus, for the development of wind turbine park at Solovetsky Islands, coordinates of location 2 give the best site area for wind turbines. The graphical comparison between locations can be seen in Fig. 4.

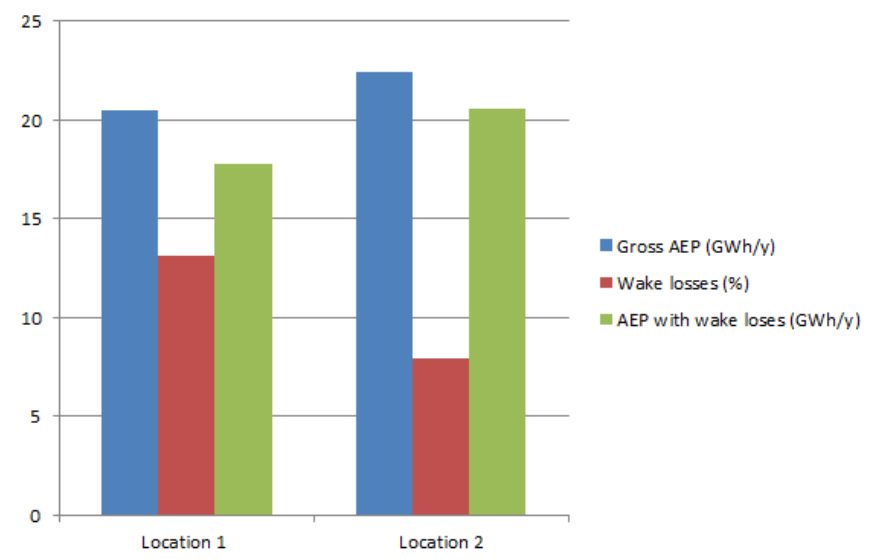

Fig. 4. Energy (GWh/y) comparison with wake losses $(\%)$

As mentioned above in the measurement data section, the data in the Solovetsky Islands are limited, because there is only one meteorological station and technical equipment is not enough. For a much better AEP estimation, data for a longer time and for different heights are needed, and it can give better accuracy about the selection of potential construction site for wind park installation.

\section{Conclusions}

The main findings of this study are listed as follows:

- During the analysis of the current energy system of the Solovetsky Archipelago, it was clarified that diesel fuel has a considerable harmful impact on the environment.

- Wind speed and wind direction data were analyzed from April 2012 to February 2018. Two variants of the location of the wind park were selected taking local conditions into account.

- The annual energy production of wind farm and wake losses were calculated for the two selected locations. The results of location 2 gave a large AEP and smaller wake losses.

\section{Acknowledgement}

This research was supported by UIT the Arctic University of Norway under Cooperative Projects within the University of the Arctic (UArctic 2017) funding. The project is titled Academic Collaboration 
for Sustainable and Energy Efficiency Development in the Arctic between The Arctic University of Norway, UiT and the Northern (Arctic) Federal University (NArFU) Arkhangelsk.

\section{References}

[1] Yue CD, Chen CS, Lee YC. Integration of optimal combinations of renewable energy sources into the energy supply of WangAn Island. Renewable Energy, 2016; 86: 930-942.

[2] Marín C, Alves LM, Zervos A. 100\% RES-A challenge for island sustainable development. Instituto Superior Techico. [Online]. Available: http://issuu.com/pubcipriano/docs/island100res/19. 2005.

[3] Alves LM Monteiro, Costa AL, da Graca Carvalho M. Analysis of potential for market penetration of renewable energy technologies in peripheral islands. Renewable Energy, 2000; 19: 311-317.

[4] Sanseverino ER, Sanseverino RR, Favuzza S, Vaccaro V. Near zero energy islands in the Mediterranean: Supporting policies and local obstacles. Energy Policy, 2014; 66: 592-602.

[5] Jiahong Liu, Chao Mei, Hao Wang, Weiwei Shao, Chenyao Xiang. Mutual adaptability of renewable energy and water-supply systems in islands. Energy Procedia, 2017; 105: 799-804.

[6] Hans CG, Sonja S. Carbon neutral archipelago - 100\% renewable energy supply for the Canary Islands. Applied Energy, 2017; 188: $342-355$.

[7] National Centers for Environmental Information. [Online]. Available: https://www.ncei.noaa.gov.

[8] Burton T, Sharpe D, Jenkins N, Bossanyi E. Wind Energy Handbook. John Wiley \& Sons, 2001.

[9] Chang TP. Estimation of wind energy potential using different probability density functions. Applied Energy, 2011; 88: 18481856.

[10] Corotis RB, Sigl AB, Klein J. Probability models of wind velocity magnitude and persistence. Sol Energy, 1978; 20(6): 483493.

[11] Garcia A, Torres JL, Prieto E, De Francisco A. Fitting wind speed distributions: a case study. Sol Energy, 1998; 62(2): 139144.

[12] Hennessey Jr JP. Some aspects of wind power statistics. J Appl Meteorol, 1977; 16: 119-128.

[13] Jamil M, Parsa S, Majidi M. Wind power statistics and an evaluation of wind energy density. Renewable Energy, 1995; 6(5): 623-628.

[14] Justus CG, Hargraves WR, Mikhail A, Graber D. Methods for estimating wind speed frequency distributions. J Appl Meteorol, 1978; 17(3): 350-353.

[15] Ozay C, Celiktas MS. Statistical analysis of wind speed using two-parameter Weibull distribution in Alacati region. Energy Conversation and Management, 2016; 121: 49-54.

[16] Rehman S, Halawani TO, Husain T. Weibull parameters for wind speed distribution in Saudi Arabia. Sol Energy, 1994; 53(6): 473-479.

[17] Rocha PAC, Coelho de Sousa R, Freitas de Andrade C, Vieira da Silva ME. Comparison of seven numerical methods for determining Weibull parameters for wind energy generation in the northeast region of Brazil. Applied Energy, 2012; 89: 395400.

[18] Shu ZR, Li QS, Chan PW. Investigation of offshore wind energy potential in Hong Kong based on Weibull distribution function. Applied Energy, 2015; 156: 362-373. 